\title{
Os Desafios e Potencialidades da (auto) formação Docente
}

\section{Challenges And Potentials Of Teacher (self ) formation}

\section{Los Desafíos Y Potenciales De La (auto) formación Maestra}

\author{
Oliveira, Wagner de Moura ${ }^{1}$ (Santa Maria, RS, Brasil) \\ ORCID ID: http://orcid.org/0000-0001-5401-9063 \\ Oliveira, Francisco Nilton Gomes de ${ }^{2}$ (Santa Maria, RS, Brasil) \\ ORCID ID: http://orcid.org/0000-0002-2293-2111 \\ Pommer, Roselene Moreira Gomes ${ }^{3}$ (Santa Maria, RS, Brasil) \\ ORCID ID: http://orcid.org/0000-0001-9380-7003
}

\begin{abstract}
Resumo
Este artigo se propõe a refletir sobre a relevância do docente olhar para si mesmo como uma pessoa em constante construção formativa, bem como, ser consciente de sua responsabilidade auto formativa, visando se qualificar para trilhar os caminhos do ensino e aprendizagem guiados ao desenvolvimento profissional e pessoal. Objetiva-se neste artigo discutir à luz da literatura a concepção do ser professor: suas potencialidades na sua (auto)formação. Como fundamentação metodológica, é baseado numa revisão de literatura. Buscou-se por meio do portal da CAPES teses e dissertações que reverberam a temática aqui proposta. No constructo teórico é dada a importância e relevância social deste debate no sentido de encorajar e conduzir a reflexão crítica do docente no seu comprometimento de (auto)formação, concretizando a potencialização da prática pedagógica deste profissional em seu dia a dia no ambiente escolar. Conclui-se segurando que a (auto)formação docente possibilita o protagonismo do docente na acepção de permitir para si uma formação crítica, reflexiva e continua que não se exaure apenas nos cursos de graduação, mas que esta busca o permita ir mais além das sistemáticas tradicionais de formação.
\end{abstract}

Palavras-chave: Formação docente. Saberes. Prática pedagógica.

\begin{abstract}
This article aims to reflect on the relevance of the teacher to look at himself as a person in constant formative construction, as well as to be aware of his self-formative responsibility, aiming to qualify to follow the paths of teaching and learning guided to professional development. folks. This article aims to discuss in the light of the literature the conception of being a teacher: its potentialities in its (self)formation. As a methodological foundation, it is based on a literature review. We sought through the CAPES portal theses and dissertations that reverberate the theme proposed here. In the theoretical construct is given the importance and social relevance of this debate in order to encourage and lead the critical reflection of the teacher in his commitment to (self)formation, realizing the potentialization of the pedagogical practice of this professional in his daily life in the school environment. We conclude by holding that the (self) teacher training enables the protagonism of the teacher in the sense of allowing for a critical, reflective training and continues not only exhaustive in undergraduate courses, but that this search allows him to go beyond the systematic traditional training.
\end{abstract}

Keywords: Teacher training. Knowledge. Pedagogical practice.

\section{Resumen}

Este artículo tiene como objetivo reflexionar sobre la relevancia del profesor para verse a sí mismo como una persona en constante construcción formativa, así como para ser consciente de su responsabilidad autoformativa, con el objetivo de calificar para seguir los caminos de la enseñanza y el aprendizaje orientados al desarrollo profesional. Chicos Este artículo tiene como objetivo discutir a la luz de la literatura la concepción de ser maestro: sus potencialidades en su (auto) formación. Como base metodológica, se basa en una revisión de la literatura. Buscamos a través del portal CAPES tesis

\footnotetext{
1 Mestrando do Programa de Pós-graduação em Educação Profissional e Tecnológica da UFSM. wagnermoura56@gmail.com

2 Docente do Programa de Pós-Graduação de Educação Profissional e Tecnológica do Colégio Técnico Industrial de Santa Maria- UFSM. niltonufrj@gmail.com

3 Docente da Universidade Federal de Santa Maria. roselenepommer@ctism.ufsm.br
}

Revista Labor, V. 2, N. 24

DOI: https://doi.org/10.29148/labor.v2i24.60202 http://www.periodicos.ufc.br/labor/index

ISSN: $1983-5000$ 
y disertaciones que reverberan el tema propuesto aquí. En el constructo teórico se le da la importancia y relevancia social de este debate con el fin de alentar y liderar la reflexión crítica del profesor en su compromiso con la (auto)formación, realizando la potencialización de la práctica pedagógica de este profesional en su vida diaria en el entorno escolar. Concluimos afirmando que la capacitación de (auto)formación permite el protagonismo del maestro en el sentido de permitir una capacitación crítica y reflexiva y continúa no solo exhaustiva en los cursos de pregrado, sino que esta búsqueda le permite ir más allá de lo sistemático entrenamiento tradicional.

Palavras-Clave: Formación del profesorado. Conocimiento. Práctica pedagógica.

\section{Introdução}

O desenvolvimento de uma nova cultura profissional dos professores passa pela produção de saberes e de valores que deem corpo a um exercício autónomo da profissão docente. (NÓVOA, 1991, p. 521).

Os debates sobre (auto) formação docente e prática pedagógica têm demonstrado inquietações epistemológicas, estas, características do panorama educacional em que vivenciamos contemporaneamente. Neste lanço, vêm sendo feitos investimentos científicos com intenções de "complexificar" as experiências dos docentes, em sua condição de sujeito independente e interventor nos artifícios de ampliação do conhecimento docente. Fato este, porque já não se permite mais um professor que não seja crítico, que não seja contextualizado, carente de uma atitude reflexiva diante da solidificação dos fazeres pedagógicos.

Nesse sentido, autores como Freire (2004), Josso (2002, 2004), entre outros pesquisadores e estudiosos do tema, partilham da indigência de se indagar esta temática, maquinando para a relação entre as extensões da subjetividade do docente e os procedimentos de autogestão do exercício pedagógico. Por exemplo, na epigrafe destinada a este capítulo, Nóvoa (1991), traz como precaução a seriedade de se construir conhecimentos autos-significativos, criados por sujeitos autônomos e concisos de suas próprias experiências de formação pedagógica e educacional.

Tal necessidade se exacerba, ainda mais, de modo que, ponderamos e analisamos a sociedade moderna, pautada no acrescentamento tecnológico e na heterogeneidade cultural, o que instiga a redimensiones das sugestões de (auto) formação docente, com vista a que se formem como contributos à delineação de uma ocorrência sócio-educacional que seja complacente ao contentamento profissional e pessoal do professor, no que pertence às prestezas pedagógicas e didáticas, crescidas dentro do espaço da escola. 
Abarcamos, assim, que as questões educacionais levantadas nos domínios escolares rezingam por uma atuação docente inovadora, adversa às configurações tradicionais concretização do desenvolvimento dos professores, às quais não se têm alcançado equacionar as carências do processo de ensino e aprendizagem, nem, também, buscado proteger a autonomia do docente na edificação de seu percurso pedagógico.

Orientados por esta concepção, percebemos que inovações e novas táticas de formação devem ser adolescidas, ponderando os objetivos da educação para o mundo contemporâneo, e considerando a história de vida de cada docente. A Formação docente, nesta acepção, deve repudiar a visão formalista clássica, compactuada em uma educação apática e deve-se então, progredir rumo a uma educação social, a qual entende o professor no seu pleno e constante procedimento de formação, transformando, com autonomia e livre-arbítrio, seus despenhamentos de ser e de atuar no dia-a-dia escolar. Este artigo objetiva discutir à luz da literatura a concepção do ser professor: suas potencialidades na sua (auto)formação.

\section{Metodologia}

Este artigo é baseado numa revisão de literatura. Buscou-se por meio do portal da CAPES teses e dissertações que reverberam a temática aqui proposta. Foram utilizados os descritores formação docente, e auto- formação, cujo intenção de contemplar as produções do período entre 2017 e 2018. Esta escolha se deu por um critério aleatório.

\section{Constructo teórico}

No presente constructo teórico, o texto estará organizado em duas subdivisões, que se articulam na problemática do elemento desta pesquisa, as quais são: "formação: estruturas e sentidos"; "a formação do sujeito por si mesmo e o sujeito da formação e "singularidades do processo de (auto) formação docente na práxis pedagógica.".

Fundamentamos, então, uma divisão em segmentos de maneira a organizar o conteúdo deste capítulo em divisões características, com a intenção de invento puramente didático, até mesmo porque têm-se uma linha semântica que liga estas duas bases da investigação, solidificando a independência entre os mesmos, e 
o contrassenso de interpreta-los como partes distintas do conjunto hermenêutico dos elementos deste estudo.

De maneira imediata, consideramos analisar as particularidades periódicas nos processos de (auto) formação e seus subsídios para a conformação da profissão docente. E, no encadeamento, concretizamos a realização de um paralelo analítico entra a (auto) formação e suas alusões na realização da prática pedagógica.

Nestas ponderações, observamos para a acuidade da (auto) formação para a edificação dos fazeres pedagógicos, e, desse modo, provocamos ao professor, nas suas competências de disposição do seu ambiente profissional, bem como para o caráter de inserir-se no cotidiano de ações que desempenha no conjunto educacional que que está inserido.

\section{Formação: estruturas e sentidos}

Nas últimas décadas, tem-se escrito muito sobre as expectativas em torno da educação para a atualidade e tais produções tratam de abordar um novo perfil que a escola e os docentes precisam adotar para atender às demandas da contemporaneidade (NÓVOA, 1991; PIMENTA, 2006; DEMO, 1998; JOSSO, 2001; MORIN, 1999). Diante deste novo contexto, existe um conjunto de novos potenciais e novas provocações marcados pelas mudanças econômicas, pela consolidação dos cidadãos em pautar uma melhor cidadania para todos, pautada na igualdade e participação intensa na sociedade, também pela revolução digital, as tecnologias da informação e comunicação em alta e pela sociedade do conhecimento e aprendizagem. Neste sentido a educação, bem como a formação de professores têm uma função primordial, logo, mais ampla e multiplamente complexa.

A definição do conhecimento estabelecido na sociedade contemporânea implica uma disposição à obsolescência, pelo aumento acelerado e uso intenso e demasiado da informação, o que tem sido chamado de eclosão do conhecimento, tanto em uma acepção qualitativa quanto quantitativa. O conhecimento proporciona maior complexidade e uma ideia de dúvidas sobre o mundo, mas pode ou não conferir a pessoa uma visão crítica sobre a sociedade e realidade em que vive.

É um tempo de perspectivas, de embaraços e de crise de opiniões e paradigmas, em que a sociedade do conhecimento é abrangida como aquela na qual o conhecimento tem a função principal na produção de prosperidades e de poder, 
tanto para as empresas quando para os países. Há um crescente e larga expansão das novas tecnologias de informação e comunicação (TIC), sendo este um fator importante para o crescimento e desenvolvimento econômico, principalmente de países subdesenvolvidos. Ainda assim, produzem transformações culturais expressivas, ligadas as tecnologias e, além de aguçar o sujeito a dar novos significados e a ter melhor compreensão de tempo e de espaço, assinalam para a carência de buscarem maneira de pensar e refletir a realidade. Tais fatores se dão pela ocorrência das possibilidades intermináveis de construção de realidades virtuais que os usos das TICs proporcionam. Em referência a isto, Tedesco (2001, p. 46) aconselha que:

Sua aplicação torna essencial transformar conceitos básicos de tempo e espaço. A própria concepção de realidade desperta refletir a partir das possibilidades de produzir realidades virtuais, sugerindo novas problemáticas, reflexões e questionamentos de organização epistemológica, cuja análise só atualmente foi iniciada.

A conquista e o valor do conhecimento debelam a educação e a formação de professores a novas e velhas compreensões, revigorando a tradicional relação de funções entre a escola e as benesses para a sociedade, porém acarretando em novas variantes, como a aprendizagem como abertura para organização da sociedade, e vinculando as mesmas ideias, "os que reportam a uma subordinação das relações dos seres humanos com o meio ao imperativo da satisfação das necessidades com vista à obtenção de um prometido bem-estar" (CARVALHO, 2000, p. 48).

Tal situação tenderá a ter ecos no estado individual de cada sujeito, nas limitações dos estilos de vida de cada um e da busca de investimentos em novas chances de oportunidades e habilidades de escolhas e atuações, conduzindo a vida das sociedades.

Compreende-se que boa parte dos desafios em que é dado a sociedade atual decorre em novas relações, para que se deva deixar perceber a qualidade das ações educacionais. Dessa maneira, o processo formativo deve-se apoiar-se na aprendizagem ao longo da vida e nas singularidades do sujeito em troca com a sociedade. Essa abordagem observa o fato de que o processo de educação é ativo e de desenvolvimento do sujeito em suas complexas dimensões e capacidades, com vistas a garantir a condição de livre-arbítrio e compostura humana. Tais fatores serão 
Programa de Pós-graduação em Educação, Universidade Federal do Ceará

Fortaleza-CE-Brasil

pensados no processo de (auto) formação, pelo meio de racionalidade e subjetividade, do modo como usa a inteligência e das aptidões da mente e espirito, que são razoáveis de provocar o apreensão e compreensão necessárias em face do maquinamento dos casos de ensino e aprendizagem (MORIN, 2006).

Desta maneira, é necessário suprir um pensamento que abstrai um pensamento que uma, que tire de dentro da bolha os saberes e ligue os conhecimentos (MORIN, 2006). É a ligação é categoria fundamental à substituição da causalidade linear e dimensional, que será efetuada nas referências e circularidades. A compreensão de circularidade aborda uma ação de vaivém entre fontes elaboradas dos saberes, que mudam e, pela mesma transformação, é modificada, se alinhando novamente. Tal processo acarreta em uma fissura para novas possibilidades de saberes, na seu diálogo e independência de acordo com a situação social. Já a abordagem referencial abarca um processo epistemológico que se compõe com base na importância do caráter multirreferencial dos epifenômenos sociais:

O tratamento multirreferencial parte da origem de que todos os sujeitos implicados formam e se formam em cenários plurais de situações de trabalho, ensino e aprendizagem. (ALVES, 2014, p. 22).

Isto é:

Este tratamento visa, dentre outras coisas: I) debater a existência de variadas instâncias cognitivas, onde a ciência é meramente um deles, não o único; II) tratar o objeto de forma dialética, aprovando a lógica do antagonismo; III) certificação da complexidade e da pluralidade que caracteriza as práticas sociais.

(ALVES, 2014, p. 22).

Este enfoque acende em possibilidades de construção de conhecimento da realidade de maneira mais aberta e complexa e, por conseguinte, conhecendo a necessidade de distinguir o entendimento dos acontecimentos dos sujeitos. Nesta realidade está implicada a ideia de complexidade criada por Morin (2000, p 103), em que "A consciência da complexidade nos faz compreender que não poderemos escapar jamais à incerteza e que jamais poderemos ter um saber total: a totalidade é a não verdade".

Desta maneira, uma reparação no pensamento é imprescindível, como nos profere Morin (1999, p 19): 
A mudança da austeridade da lógica clássica por uma dialógica habilitada em gerar noções ao mesmo tempo complementares e contrarias; que a sabedoria da integração das partes num todo seja aperfeiçoado pelo reconhecimento da agregação do todo no íntimo das partes.

Nessa situação, as reflexões sobre a educação se estabelecem com urgência, a fim de se buscar um meio de ligar os conhecimentos, conectar os objetos ao seu contexto, pauta-los e posiciona-los num todo, ou seja, é fundamental o pensamento complexo, pois sistematiza os saberes desordenados e abre caminho para entender melhor os problemas.

Para tanto, é necessária uma mudança de mentalidade que compreenda o processo essencial e continuado de aprendizagem, que possa ultrapassar a conexão das variáveis das ações pedagógicas e que se dirija a um novo entendimento, na passagem, em si, da (auto) formação; nos outros, da heteroformaçã e, na sociedade, da ecoformação, respectivamente. Um ato reciproco, de trocas bilaterais de saberes e conhecimentos na composição do ser, a partir do intercambio reflexivo entre o sujeito e o espaço físico e social e nas ações pedagógicas modificadas, construídas pelos saberes e conhecimentos.

A formação salientada por Morin leva como importância o autodidatismo, assinalado por um processo de aprendizagem mútua, de experiências, de trocas e de novos conhecimentos, em uma dinâmica engenhosa e de exploração subjetiva, acreditando na possibilidade de uma resposta de reflexão sobre suas próprias experiências para o refinamento de suas ações pedagógicas.

A formalização do progresso da aprendizagem por si mesmo, para Morin (1995), se dá ao consentir a desmaterialização do universo cultural, abstendo-se de considerar as possíveis verdades constantes e fixas, conferindo-se, em seu lugar, afinidades com a sociedade, "o que ajuda o espírito a contextualizar, globalizar, antecipar" (MORIN, 1999, p. 44). O conceito, para ser compreendido, deve ser implantado em uma complexa sistemática de ideias e experiências, esta deve ser contextualizada.

Pode-se assegurar que o saber, o conhecimento é uma ação construtiva constante, inexaurível, pois na vida e na ciência, não há verdades absolutas. Com embasamento nessa odeia e persuasão, é no pensamento complexo a probabilidade de um aporte teórico que harmonize uma leitura de maior compreensão, mais crítica 
e intensa, dos difíceis fenômenos da temática estudada, como possibilidade de engrandecer a leitura e análise. Presumimos que o pensamento abstruso, enquanto suposição teórica norteadora, permitindo aperfeiçoar uma análise da (auto) formação tão-só ao mesmo tempo que o saber acadêmico, analisando suas demais complexidades. A essência do pensamento complexo é balizar, mas não separar; pondera todas as extensões do sujeito e do contexto e interage o que é de procedência múltipla e diversa, afinidade que se dá entre os sujeitos, de cada ser humano consigo mesmo e com seu meio social, político, econômico, histórico, constituindo um pensamento singular de complexidade.

Ressalta-se ainda, dentre as distintas visões de formação, o pensamento de Pineau, que a defino como um processo constante e essencial de todo ser e a concepção de uma forma. Pieau nos expõe que toda vida humana origina uma aptidão para reconhecer e, mutuamente, todo conhecimento traz um sujeito interagindo de maneira reflexiva com o espaço físico, cultural e a sociedade. $O$ autor ainda acredita em uma experiência com o conhecimento, uma estruturação e modificação do ser humano frente a vida pessoal e social. Tal entendimento vai além de um olhar sociológico e educacional, no sentido de um ponto de vista antropológico.

A compreensão deque há que aprender a formar-se, a configurar-se, cunhando uma direção para a existência, tal como para a aprendizagem, está baseada em entendimento na qual a (auto) formação deve ter um destaque principal, a qual se explica pelo exercício coletivo que a liga a tudo que a cerca, levando em conta as experiências e os saberes de cada um.

\section{Singularidades Do Processo De (Auto) Formação Docente Na Práxis Pedagógica}

Abordar a formação docente a ações pautadas na racionalidade tecnicista se conforma como uma concepção do desenvolvimento profissional adverso ao valor do professor, enquanto sujeito crítico, incentivador, incrementador da definição de suas próprias formas de ser e de fazer os seus métodos pedagógicos de ensino. Ainda que, há o entendimento de uma formação como algo exterior ao sujeito, não tem cooperado para o desenvolvimento do professor, e se materializa como uma amostra de transmissão de conhecimentos, que acaba dificultando as possibilidades de inovação, de críticas e de inventividade nas veemências do exercício pedagógico. 
Desta forma, abarcamos que um entendimento concreto de formação, que acrescenta a estatura técnica do trabalho docente aos demais jeitos do artifício do ensino e aprendizagem, partilha as habilidades de o sujeito pensar a constituição de seu próprio caminho formativo, distinguindo-se como uma pessoa que se modifica, transformando a si próprio e seu lanço de convívio. Neste ponto de vista, a (auto) formação se configura um tanto como incompleto, com lacunas para mudanças e, adiante de tudo, torna-se um procedimento valorativo das esperanças e necessidades do indivíduo que se forma.

Orientados por este entendimento, atendemos o processo de (auto) formação como um ativo de construção de conhecimentos e experiências profissionais de um sujeito que atua na consciência do desempenho que cumpre na transformação própria realidade e da totalidade do contexto social que em que está inserido; e, desta maneira, entendemos a (auto) formação como um exercício prático de incremento centrado nas aptidões pessoais e intrapessoais de avaliar as vivências diárias, o que se determina como um caráter próprio de ser e de operar, em prol da mutação das experiências consubstanciadas das agilidades da profissão docente.

Desta maneira, a consciência de formação molda-se com a de processo e trajeto da vida pessoal e profissional, que não se finaliza, mas que se direciona a um percurso permanente de novidades e inovações ininterruptas. $E$, pelas transformações cada vez mais aceleradas que está acontecendo na sociedade, e, ainda, perante as novas questões que se depositam na escola, é essencial que o docente desenvolva um perfil diferente de formação, que the confira um trabalho pedagógico independente e livre, de reflexões acerca das agitações pessoais e das perspectivas sociais.

Assim sendo, a concretização de um estudo como este, focalizado na (auto) formação e saberes de docentes, nos permite avaliar o papel do professor no desenho das maneiras de ser e construir conhecimentos educacionais proeminentes a consolidação da prática pedagógica. Percebe-se, assim, que a (auto) formação aprecia as narrativas de vida acerca dos trajetos educacionais caminhados pelo sujeito que se forma, o qual acaba revivendo ocasiões acentuadas, que deliberam as experiências características do percurso profissional do professor.

Desta maneira, compreende-se que "a história de autoformação proporciona uma parte da vida: aquele durante o qual o sujeito esteve implicado numa 

o pensar reflexivo como um processo de visitação e de crítica do caminho de formação, um espaço cômodo ao autoconhecimento e a aceitação de consciência sobre os trajetos de (auto) formação.

Este fato, aguça a ideia de que "[...] ninguém forma ninguém e a formação é, inevitavelmente, um trabalho de reflexão sobre os percursos da vida" (NÓVOA, 1988, P.116). Tais ponderações se alinham ao fato de que o pensamento reflexivo do docente propicia a (re)edificação concisa de si próprio e de sua direção pessoal e de experiências na sua formação.

Essa consciência de reflexões do professor, como percebe Dias (2010), implica que a mudança da prática decorre de uma ação de emancipação profissional, gerido por um procedimento de (auto) formação consciente das questões pedagógicas e da obrigação e necessidade de atualização social das atuações docentes, o que vale para se impedir o dogmatismo e a afeição aos entendimentos educacionais superados, que atrapalham a construção de um trabalho docente inovador.

De maneira mais aberta, podemos compreender a (auto) formação algo essencial ao professor, na sua circunstância educacional sólida, e compreende aspectos relativos às extensões pessoais e sociais do desenvolvimento do professorado. Para tanto, dá-se ênfase "[...] ouvir a voz do professor, para dela extrair considerações que permitam compreender a gênese e a evolução das aprendizagens concernente ao desenvolvimento do exercício docente" (SOUZA, 2006, p. 55).

Assim sendo, espaçamo-nos das apreciações impetuosas, fomentadas por soluções imaginativas carentes de uma fundamentação cientifica mais ampla, e, assim, levantar um investimento epistemológico baseado pela verdadeira expressão dos sujeitos, o que profere as ações científicas aos acontecimentos tecidos no colóquio das realidades educacionais.

É relevante problematizar os desígnios que orientam a (auto) formação dos professores e professoras que serão analisados no estudo, assim como, a maneira como produzem suas atividades pedagógicas. Entende-se, de imediato, que 0 docente se torna sujeito de si mesmo, quando abrange e enxerga o caminho percorrido na construção de seu percurso profissional e formativo, desbravando os modos de se administrar na concretização das atividades pedagógicas. 

educativa resulta de grande parte da importância que confere a esta ação. Dominicé (2010) explana, nessa acepção, que não há formação em transformação ou intenção, por mais que muito parcial, de um aparelho de menções ou de compreensões da realidade. Isso aprova o fato de que os sujeitos podem compreender a vida diária, os seus percalços e os contrassensos, bem como as crises que vivem, difundindo a analisar a própria historicidade e os atos cíclicos na construção da mesma.

Sob esta visão, na construção do procedimento de (auto) formação docente, o professor não é um mero expectador, mas é uma parte fundamental na captação desse processo, o que manifesta que os processos de (auto) formação devem levar em apreço não ao volume tecnicista ou cronológico das atuações formativas, mas o papel do professor e suas alusões na acepção de seu próprio incremento profissional. Assim sendo, as ações investigativas no campo da (auto) formação de professores devem provocar para as habilidades pessoais de fazer e abranger os processos educacionais.

Dirigidos por essa compreensão, Josso (2002), compreende que o professor produz imagens sobre o seu próprio caminho formativo, e fundamenta-se um sujeito criativo que se visita e se avalia dentro de suas experiências mais expressivas às mudanças e à reordenação dos referenciais da vida profissional. $O$ docente, portanto, institui suas vivências, modificando a si mesmo como ator principal de sua própria história de vida e formativa, e, nesse sentido, torna-se construtor de sua própria história e modo de vida, que profere os aspectos pessoais do incremento das tarefas pedagógicas com as afinidades pessoais e dentro do seu contexto, construídas nos ambientes escolares.

As tensões das dimensões individuais da (auto) formação docente com as dimensões da prática pedagógica torna-se indispensável para a solidificação do processo de ensino e aprendizagem e o direcionamento do "ser professor", diante das cobranças da sociedade contemporânea. Analisa-se, então, que esse processo é substancial as diferentes maneiras de se penar, repensar e propor transformações educacionais acentuadas às atividades pedagógicas adiantadas nos espaços das escolas, o que contradiz as experiências independentes de se concretizar o trabalho docente no contexto escolar. 
Podemos adicionar a essas alegações o fato de que é acessível, nos debates sobre educação, o conceito que que a formação é bastante expressiva à prática pedagógica, de maneira que a qualidade do ensino está congruentemente ligada a um processo adequado de formação de professores. Nóvoa (1995, p.9), elucida que "[...] não há ensino de qualidade, nem reforma educativa, nem inovação pedagógica, sem a adequada formação de professores. " Diante desta compreensão, a formação docente estabelece-se estamento crucial na efetivação das transformações educacionais, e, como tal, necessita mostrar-se apropriada aos acabamentos que se propõe, de maneira a poder dar respostas o suficiente as pretensões dos sujeitos nas diferentes veemências sociais.

Essas exposições comprovam que a (auto) formação docente se realiza nos diversos ambientes das vivências e experiências do docente, arrebatando-se como um processo extenso e permanente que profere as dimensões pessoais com as questões emergentes nos conjuntos educacionais, episódio que une a vida e a profissão docente. Assim, expõe que o docente nunca está pronto, suas ações de formação não se concluem nos cursos ordenados que são promovidos pelas instituições ou ambientes acadêmicos de formação profissional. A (auto) formação docente é consecutivamente uma realidade variável, e ocorre num processo cíclico que se abre para toda vida, através de atos que abarcam os aspectos do sujeito e das experiências como docente.

As práticas (auto) formativas docentes são investimentos que o professor faz para si num processo continuado e regular, atrelado as suas vivências educacionais. Assim sendo, o docente pensa e avalia a materialização de seus conhecimentos, procurando construir seus espaços e jeitos de ação profissional, com aspecto à melhorias e qualidade de sua prática pedagógica.

Dentro desta lógica, podemos debater a (auto) formação como uma prática educacional de propriedade do sujeito que se forma, o qual dá significados particulares para os sentidos de seus conhecimentos pedagógicos. Com tudo, chamase a atenção para o professor, analisando-o na sua integridade de um ser criativo e ativo na sociedade, incluso em uma instância de um processo individual, com estímulos a ajustar-se nas configurações de sua concretização prática pedagógica. Desta forma, procuramos não entender a (auto) formação como uma prática 

maneiras dentro das experiências profissionais dos professores.

Lembrando que a (auto) formação não se emancipa em um processo independente e estagnado, mas através de constantes inspirações e reflexões de pensamentos e atitudes, que veste as experiências dos docentes como base para a consolidação dos planos e atitudes que são circulares no âmbito educacional. Nessa circunstância, nascem as novidades e sugestões pedagógicas expressivas, e é, nesta questão, que notamos a proximidade do "eu professor" com as acepções mais simples de significações da profissão docente.

Desta forma, a (auto) formação não pode ser atrelada ao individualismo ou a um sujeito autodidata, nem tampouco, com a imagem de "faça você mesmo" (NÓVOA, 1995), uma vez que o docente, mesmo que autônomo de poder fazer e poder ser, não trilha seus caminhos sozinho, este docente está inserido em um entorno social, o qual interatua constantemente, numa totalidade complexa e múltipla, em que passa por constantes transformações.

A (auto) formação docente pode ser vista como uma sugestão de desenvolvimento lógico do professor, atrelado as suas devidas necessidades, o qual constitui-se como papel importante na sua formação. Desta forma, podemos observar que "[...] o ser vivo não é só resultado ou produto de indivíduos, mas parte de individualização" (SIMONDON, 1965, p. 21).

O professor em formação, se ergue e se modifica em variadas situações interpessoais, em tarefas intrincadas a preparação de conhecimentos múltiplos, nascidos por traçados pessoais acomodados às capacidades individuais de concepção da realidade. Neste segmento de (auto) formação não são analisados os ambientes para a concretização de uma prática pedagógica adequada, o que acaba ficando distante das ambições pessoais e da realidade escolar.

Compreendemos a (auto) formação como uma possibilidade aberta a reflexões, ou seja, a compreensão de acréscimo em que "[...] o indivíduo ou grupo se torne para si mesmo ou seu próprio fim, a sua própria transcendência" (BAREL, 1985, p. 287). As ações autoformativas é destacada nas experiências geridas pelos sujeitos que se autoconstroem e fundam estruturas próprias de mudanças do meio em que se estão. 
Tais considerações podem ser acrescentadas pelo fato de o professor, então, na sua inquietação pessoal, adolescer maneiras de intervir na prática pedagógica, distanciando-se dos modelos institucionais que o formaram, a procura de um comportamento autoreflexivo na concretização dos saberes e fazeres docentes. Essa própria abordagem interpretativa está respaldada em Perrenoud (1995, p. 185), ao abordar a formação como uma técnica ampla de múltiplas agitações, heterogeneidade de circunstâncias e pontos de vista, o que demanda do professor [...] ingresso e destreza na habilidade de resolver problemas difíceis e variantes, diante de uma ética e responsabilidade, capaz de ter sua autonomia.

Diante destas considerações de Perrenoud (1995), prevalece o apreço pela racionalidade crítica e reflexiva dos procedimentos de (auto) formação, a qual observa o sujeito como atuante de suas ações de aprendizagem, posicionando-o dentro de uma camada de desenvolvimento empenhada com os conhecimentos e as atividades geridas pelo sujeito no seu ambiente de desempenho profissional.

Compreendemos, dessa maneira, a (auto) formação docente numa afinidade com a prática de refletir, pensar e executar as ações educacionais, e não como uma mera atividade que não há relevância de significados sociais. Tal entendimento de autodesenvolvimento centraliza-se na epistemologia individual de diagnóstico dos fatos educativos, a qual, segundo Pimenta (1997, p 44), estabelecese, diante

A acepção de que cada docente, como protagonista ou autor, examina à atividade docente, no seu dia a dia, com alicerce em seus princípios, sua moral, modo de se posicionar no mundo, seus saberes, suas preocupações e seus anseios, na lógica que tem em sua vida o ser professor, assim como em sua teia de relações com outros docentes no cotidiano social.

Assim sendo, podemos perceber que as construções de formação docente, educacionalmente e socialmente falando, sejam relevantes e resultem de uma demonstração de subjetividade e se constitua para o docente como uma passagem a ser trilhada para investir em algo promissor e "[...] encontrar o seu projeto de ser e se formar-se" (CHANÉ, 1988, p. 96), em um procedimento constante de construção de significados para as experiências traçadas durante das vivências profissionais.

Nesta situação, o docente responde por sua própria atuação, enquanto ser atuante de construção de conhecimentos e, assim, alimenta-se "[...] no que é, no que 
Programa de Pós-graduação em Educação, Universidade Federal do Ceará

Fortaleza-CE-Brasil

faz, no que pensa e no que diz" (ALARCÁO, 2004, p. 64). Desta maneira, delineia-se os caminhos de sua formação, atentando uma responsabilidade e uma capacidade singular as ações e dos jeitos de ser e de fazer-se professor.

É evidenciado que o método dialógico de formação docente está precedido da capacidade de o docente procurar achar respostas as próprias inquietações, exercício este, que se dá de forma autônoma, acompanhado de aspectos subjetivos e às obrigações de mudança social. Trazendo uma reflexão do filósofo Sócrates, segundo o mesmo, a verdade deve ser descoberta pelos próprios sujeitos no seu interior e promover inquietações de questionar a si próprios sobre o significado dos acontecimentos existenciais.

No transcorrer desta confabulação, o filósofo Sócrates elucida Mênon que cada pessoa deve buscar respostas para seus problemas num procedimento de autodescoberta das potenciais desenvolturas do desenvolvimento subjetivo de si próprio, o que contradiz a amarração doentia do homem às obrigações sociais (PLATÃO, 1951). Diante testes argumentos, coloca-se a (auto) formação docente, a qual deve ser abarcada como ampliação do "pessoal" que é diretamente ligado ao "profissional". Ainda que, é cômodo na vida dos homens todo um método de busca das extensões pessoais com as incertezas da formação profissional, porque é conveniente da natureza de cada pessoa a ousadia de concepção e de modificação da realidade.

Desta forma, instiga-se o professor, no cenário de suas ações pedagógicas, ambiente em que elucida e compreende as atividades educativas que desenvolve, mostrando-se administrador das práticas pedagógicas que desenvolve nos espaços escolares. Para tanto, nesse estudo, o foco está nas práticas de (auto) formação, associando as peculiaridades subjetivas do desenvolvimento profissional a aplicação de uma nova pedagogia de formação, marcada por uma prática de educação emancipatória, de seriedade com os anseios profissionais e pessoal de cada docente.

Dessa maneira, debatemos a (auto) formação como uma ação de autodiretriz de construção de aprendizagens, de propriedade do próprio docente, o qual se (re)avalia nas ligações que estabelece consigo mesmo e no seus arrabaldes sociais. Procurando implantar dinâmicas mais expressivas para o seu progresso profissional. Permanecendo em (auto) formação, o docente se conhece e se transforma, transfigurando seu processo formativo reciprocamente. Assim, o 
professor, inicia uma reflexão sobre os fundamentos e os propósitos de suas práticas, remodelando o seu percurso de ação pedagógica.

Partindo deste entendimento, interpretamos a (auto) formação como uma prática comunicativa das ações, das reflexões e das experiências docente, ao momento em que permite começos sintéticos para reflexões contates sobre as práticas pedagógicas exercidas nos ambientes escolares. Trazendo sua consideração Nóvoa (1988, p. 117), apresenta que "[...] é a própria pessoa que se forma e forma-se na medida em que elabora uma compreensão sobre o seu percurso de vida: a implicação do sujeito no seu processo de formação torna-se inevitável. "

A (auto) formação é um conceito importante nesta pesquisa, sobretudo, pelas suas contribuições, que se distinguem e ao mesmo tempo se complementam. É importante destacar a ideia do sentido formador, este, ligado às bases filosóficas, pondo a (auto) formação ao emprego do processo de construção do conhecimento, a procura de algo que realmente faça sentido, como mostra Severino (2011, p. 03): "É por tudo isso que não pode haver educação, verdadeiramente formativa, sem a participação, sem o exercício e o cultivo da filosofia em todos os momentos da formação das pessoas".

A manifestação da (auto) formação, nesse sentido, é compreendida como o aceite da decisão no momento em que a construção de saberes é aguçada, o que incide na capacidade de ruptura do pensamento e o estabelecimento de novas formas de pensamentos, ou seja, há uma regeneração no modo de pensar. É importante destacar o valor dado aos saberes científicos, a criatividade, as relações de autonomia e a diversidade.

Para Freire (2003), tal postura de desenvolvimento de pensamentos, exige do educador, este que está sempre em constante aprendizado, ter o diálogo permanente com as suas concepções interiores e os aspectos sociais, e ainda, ter uma atitude intensa de (auto) formação para que aguce e provoque circunstâncias para reflexões e propicie um espaço onde possa se aprender de forma livre e satisfatória.

A (auto) formação docente se forma, assim sendo, um processo formativo proporcional ao que o docente almeja e um processo inovador, oposto aos padrões positivistas categóricos dos modelos de formação tradicional, até porque, na sociedade contemporânea, permeada por tecnologias inovadoras, ficam claras as 
críticas por uma formação docente intensa e inovadora, visto que o educador precisa estar sempre em constante atualização (MATURANA; VARELA, 2004); e, ao docente cabe desenvolver metodologias pedagógicas expressivas aos seu próprio desenvolvimento pessoal, pois, somente desta maneira, estabelece e cria experiências coesas com as suas expectativas profissional e pessoal, no sentido de estar realizado plenamente.

O método autoformativo demostra, desse modo, que "[...] não há saber se não para um sujeito, não há saber se não produzido em uma confrontação intra e interpessoal" (CHARLOT, 2000, p. 61-67), e que a afinidade com o saber submerge o outro, mas fica centralizado nas disposições de compreensão da realidade. Tal fato mostra que o sujeito, que convive diretamente construindo e regenerando seus conhecimentos, apropria-se do mundo, mas não se deixa domar por ele, visto que, nesse evento, "[...] aprender faz sentido por referência à história do sujeito, às suas expectativas, à sua concepção de vida, às suas relações com os outros, à imagem que tem de si e à que quer dá aos outros" (CHARLOT, 2000, p. 72).

Tal postura de desenvolvimento autoformativo é fundamental para a carreira docente, pois, o ambiente educacional da atualidade está exigente na presença de profissionais críticos e reflexivos, que acreditem no valor e importância de seus atos para a transformação dos modelos pedagógicos tradicionais. A escola hoje está mudada e há um nítido aclame social por professores inovadores e reflexivos, os quais tenham saberes maiores de educação, expressiva, para tanto, para o enfrentamento diário de circunstâncias de conflitos escolares e de suas próprias inquietações referentes aos fazeres pedagógicos.

É evidente que as metodologias de formação de professores são invariáveis, o que não se adequam às novas reclamações educacionais exigidas pela sociedade contemporânea; é necessário haver uma prudência maior com a formação docente dinâmica e inovadora, pautada na reflexão das atuações educacionais estabelecidas na sociedade atual. Nesse sentido, corrobora Lévy (1999, p. 2) que:

A procura por formação não somente está passando por um crescente quantitativo, mas como também está passando por uma transformação qualitativa, no sentido de uma progressiva necessidade de diversificação e customização. Os sujeitos suportam cada vez menos participar de cursos uniformes ou severos que não convém às suas expectativas e necessidades e a característica de seu trajeto de vida. 
A (auto) formação surge como uma escolha na formação que possibilita se abrir para novas dimensões e efetivações de métodos mais abertos de ações pedagógicas, ou seja, lugares onde o docente estabelece e formula seus objetivos, percebe os outros sujeitos e os recursos necessários para à consolidação de seu trabalho, podendo propor e praticar suas estratégias focadas no ensino e aprendizagem, de acordo com as emergências sociais.

Desta maneira, aparece a compreensão de que o docente deve lutar pelo progresso e qualidade da prática pedagógica, o que querendo ou não, implica em empenho pessoal, ânimo e envoltura na implementação de ações pedagógicas permanente, bem como, saber ouvir, agir e falar criticamente, pensando no seu aprendizado diário da profissão, este que é fruto de uma educação reflexiva, na qual abarca "[...] entusiasmo, definido como a predisposição para enfrentar as situações diversas com curiosidade, energia, prazer, capacidade de renovação, ruptura com a rotina" (GARCÍA, 1993, p. 62).

A (auto) formação, tendo em vista se caráter autônomo, colabora para que o docente possa propor seus métodos, constituir objetivos na sua desenvoltura profissional, baseando-se que cabe ao docente em formação autônoma medir as consequências de suas disposições e comprometer-se para obter e buscar seus objetivos, podendo fazer mudanças, avançando ou retrocedendo no enfrentamento dos desafios diários da sua ação docente.

Nesta interpretação, a (auto) formação mostra-se como uma opção viável para o desenvolvimento do docente e se estabelece como a práxis do viver do professor, gerida por uma consciência sobre os métodos, técnicas e teorias de ações da prática pedagógica. Fica evidente, que as dinâmicas de (auto) formação demandam uma capacidade de o docente pensar o que quer para a sua vida, seus projetos, objetivos e capacidades, no qual pode ainda refletir sobre suas necessidades enquanto sujeito ativo na sociedade, bem como, transformar-se para ter uma desenvoltura melhor dentro dos domínios educacionais.

O professor, atuante de sua formação, forma-se na relação de si mesmo (autoformação), na troca de experiências com os outros sujeitos ativos (heteroformação), e na relação com o mundo e sociedade em que está inserido (ecoformação) (MORIN, 2010). Desta maneira, a formação docente é uma realidade 
de múltiplos fatores e compreensiva da diversidade social, e assim, colabora para a estabilidade das ações e funções dos docentes.

Deste modo, a participação docente compartilhada forma experiências que enriquecem a reflexão sobre os processos autoformativos, o que possibilita uma nova dimensão das vivências e interações pessoais. Nesse sentido, idealiza-se as dinâmicas de (auto) formação como parte de uma ação mais ampla da ecoformação e da heteroformação, que posiciona as aprendizagens educacionais dentro de uma dinâmica de organização de parcerias, destas abarcam, segundo Capra (2001, p. 233), que:

A disposição para formar ligações, para organizar associações, para viver dentro de outro organismo, para auxiliar é um dos atestados de qualidade da vida. À maneira que uma união se processa, cada sujeito passa a entender melhor as carências um dos outros. Em uma parceria verdadeira e segura, ambos sujeitos aprendem e se transformam, eles passam a evoluir.

A Lei de Diretrizes e Bases da Educação - LDB 9394/96 faz menção à (auto)formação, quando entende que uma das competências da formação docente a administração e autonomia do próprio desenvolvimento profissional, o que envolve as competências de construção de metodologias didático-pedagógicas mais ativas e apropriadas aos fazeres docentes, bem como a disposição de se ter uma postura flexível na prática profissional, aspecto importante para o acolhimento das exigências pessoais e dos processos educacionais. Desta maneira, o docente foge do fracionamento do conhecimento e constitui uma atuação autêntica de sua prática profissional, baseada na constante ação de reflexão pedagógica.

Ao progredirem em seus processos de (auto) formação, os docentes constroem outras maneiras de concretizar suas ações, na perspectiva da realização das ações pedagógicas mais dinâmicas e auto-significativa, capaz de acolher às expectativas próprias e as que estão inseridas no seu presente dentro do seu contexto e inserção social. Desta maneira, compreendemos que o caráter da (auto) formação do docente está horizontalmente relacionado às condições individuais e contextuais dos ambientes e tempos dos fazeres docentes.

Para tanto, o docente em (auto) formação se acaba se compreendendo, compreendendo também o outro e o seu contexto social, adquirindo experiências, assim, de maneira particular e reservada, a possibilidade de colaborar com a 
qualidade da sua própria (auto) formação e o desenvolvimento do outro. Assim sendo, a formação não é compreendida como uma simples assimilação imprevista de regulamentos institucionais já dados, difundidas pelos sistemas mais tradicionais e educação formal, mas sim, como uma prática de desenvolvimento, amparada nas aptidões criadoras de realização das ações referentes ao processo de ensino e aprendizagem.

É, exatamente nesse sentido de entendimento, que a maioria dos educadores acodem a ideia de que a escola seja de fato e que venha a ser um ambiente inovador, autêntico, possibilitando a (auto) formação de docentes, partindo do pressuposto de que, nela, desempenhamos ações diversificadas e múltiplas, assim, também, fundamos relações intensas com os outros sujeitos do processo de ensino e aprendizagem, transformando a si próprios e na maneira de compreender a sociedade. Nóvoa (2000, p. 24), por exemplo, entende que:

É no ambiente de cada escola, em volta de problemas pedagógicos ou educacional, que se fortalece a verdadeira formação. Universidades e pesquisadores são importantes no desenho metodológico e teórico. Porém todo esse conhecimento somente terá validade, se o docente conseguir integra-lo em sua prática pessoal e articular ao seu processo de evolução.

As exposições do autor reforçam o valor do diálogo e das práticas de aprendizagens partilhadas para o autoconhecimento e para a concepção do espaço em que estamos inseridos. Para tanto, conhecer o outro sujeito como parte de nossas histórias de vida, nos auxilia na compreensão e a enriquecer o que somos, raciocinamos e agimos, no campo educacional, aguçando a ideia de que precisamos aprender a conviver juntos, para compreender melhor a nós mesmos e os outros sujeitos, num plano e concepção de convivência coletiva na sociedade.

Desta maneira, tal dimensão orgânica da (auto) formação não se compõe em um sistema estruturalmente já dado e, 'intervencionalmente' fechado, mas em um processo 'autoinspirador' de concretização dos fenômenos sociais. Desta forma, compreendemos que refletir a formação docente como uma organização autônoma que seja interativa, denota vê-la e pensa-la articulada a aspectos pessoais do desenvolvimento profissional às qualidades práticas das ações educacionais, posicionando o sujeito em (auto) formação como um sujeito capaz de abranger seus 
horizontes de ações, estudando novas metodologias de ensino e aprendizagem para transformar sua própria trajetória pessoal e profissional.

É, neste mapa interpretativo, que o estudo da problemática referente às demandas de ensino e aprendizagem tendem a se diferenciar-se e enraizar-se, considerando o docente como agente que progride, dentro de um olhar multifacetado de interferências na construção das ações referentes à formação e à prática do docente na sua profissão.

Essa atitude autônoma é necessária, pois, cada vez mais, as ações educacionais demandam do professor a mobilidade de soluções pedagógicas e da esperteza profissional, não somente os respectivos aos aspectos de ações metodológicas, mas, principalmente, os que permitem uma reflexão ampla e densa sobre as maneiras de ser professor e de se concretizar a prática pedagógica.

\section{Considerações Finais}

Essa extensão de ampliação profissional se compõe a um exercício de (auto) formação, a qual alude nas atitudes de concretização do aprendizado pedagógico, apreciando o sujeito que se desenha em sua formação e seus modos de decodificar as experiências intrínsecas à realidade da educação. A composição desse método demanda, então, trazer a história de vida do docente, o qual este, estabelece suas próprias narrativas que promulgam feições marcantes da formação e do desempenho docente frente a sala de aula, cooperando, pois, na significação do ser professor.

Com esse esboço, enraíza-se as discussões na abordagem da temática, buscando proferir os processos de (auto) formação às discussões e reflexões da ação pedagógica, partilhando do entendimento de que os conhecimentos de autoaprendizagem desempenham abundantes implicações nas maneiras de ser e de fazer-se professor, o que ratifica que o amadurecimento profissional do docente está atrelado as feições essenciais ao contexto educacional e as dimensões multiculturais da desenvoltura do docente.

Tais exposições mostra uma visão aguçada da complexidade de Morin (1999, p. 12), o qual elucida que "[...] uma educação só pode ser variável, se for uma educação integral do ser humano. Uma educação que se dirige a totalidade aberta do ser humano e não apenas a um dos seus componentes.". Com base nesta 
explanação, percebemos que é emprego de a sociedade lutar por uma gênese de formação docente moderna, ou seja, que aprecie o professor na sua grandeza afetuosa, pedagógica - alinhada a técnica pedagógica - e práticas de relações mútuas, a fim de que o seu incremento profissional colabore na constituição de um procedimento de ensino e aprendizagem significativos parra o desenvolvimento do docente e ao contexto social ao qual este está colocado.

\section{Referências Bibliográficas}

CARVALHO, A. D. de. Conhecer, pensar e educar: os desafios de uma interpelação antropológica. In: CARVALHO, A. D. de et al. Novo conhecimento, nova aprendizagem. Lisboa: Fundação Calouste Gulbenkian/Serviço de Educação e Bolsas, 2001. p. 18-19.

DEMO, P. Desafios modernos da educação. Petrópolis, RJ: Vozes, 2000a.

DOMINICÉ, $P$. O processo de formação e alguns dos seus componentes relacionais. In: NÓVOA, A; FINGER, M. O método (auto)biográfico e a formação. Natal, RN: EdUFRN; São Paulo, SP: Paulus, 2010. p. 83-95.

FINGER, M. (Org.). O método (auto)biográfico e a formação. Lisboa, PT: Ministério da Saúde, 1988. p. 89-97.

FREIRE, P. Pedagogia da autonomia: saberes necessários à prática educativa. 33. ed. São Paulo: Paz e Terra, 2006.

Pedagogia da esperança: um reencontro com a pedagogia do oprimido. São Paulo: Paz e Terra, 1992.

Pedagogia do oprimido. 5. ed. São Paulo: Paz e Terra, 1978.

GALVANI, P. A autoformação, uma perspectiva transpessoal, transdisciplinar e transcultural. Conferência proferida no II Encontro Catalisador do Cetrans da Escola do Futuro da USP, Guarujá, 8-11 jun. 2000. In: SOMMERMAN, A.; MELLO M. F. de; BARROS, V. M. de (Org.). Educação e transdisciplinaridade II. São Paulo: Triom, 2002.

GARCÍA, C. M. Formação de professores para uma mudança educativa. Tradução de Isabel Narciso. Porto, PT: Porto,1999.

A formação de professores: centro de atenção e pedra-de-toque. In: NÓVOA, A. (Coord.). Os professores e a sua formação. 2. ed. Rio de Janeiro: Paz e Terra, 1992. 
JOSSO, M. C. Experiências de vida e formação. Tradução José Claudino e Júlia Ferreira. São Paulo: Cortez, 2004.

MORIN, E. Amor, poesia, sabedoria. Tradução Edgard de Assis Carvalho. 2. ed. Rio de Janeiro: Bertrand Brasil, 1999a.

Educação e complexidade: os sete saberes e outros ensaios. Organização de Maria da Conceição de Almeida e Edgar Assis Carvalho. São Paulo: Cortez, 2002a.

NÓVOA, A. Formação de professores e profissão docente. In: NÓVOA, A. (Coord.). Os professores e sua formação. Lisboa: Dom Quixote, 1995. p. 9-33.

NÓVOA, A (org). Os professores e a sua formação. Lisboa: Dom Quixote, 1998.

Os professores e as histórias da sua vida. In: NÓVOA, A. (Org.). Vidas de professores. Porto: Porto, 1992. p. 11-30.

Professor se forma na escola. Nova Escola, Rio de Janeiro, n. 142, maio 2001. Disponível em: <http://revistaescola.abril.com.br/formacao/formacaocontinuada/professor-se-forma-escola-423256.shtml>. Acesso em: 31 jul. 2019.

NÓVOA, A.; FINGER, M. (Org.). O método (auto) biográfico e a formação. Natal, RN; São Paulo, 2010.

NÓVOA, Antônio. Professores: Imagens do futuro presente. Lisboa: Educa, 2009.

NÓVOA, A. Diz-me como ensinas, dir-te-ei quem és e vice-versa. In: FAZENDA, Ivani Catarina Arantes (org.). A pesquisa em educação e as transformações do conhecimento. São Paulo: Papirus, 2005.

PERRENOUD, P. Construir as competências desde a escola. Porto Alegre: Artmed, 1999.

Dez novas competências para ensinar. Porto Alegre: Artmed, 2000.

Quixote, 1993.

Práticas pedagógicas, profissão docente e formação. Lisboa: Dom

PINEAU, G. Autoformação no decurso da vida. Disponível em: $<$ http://cetrans.com.br/textos/a-autoformacao-no-decurso-da-vida.pdf>. Acesso em: 31 jul. 2019.

PLATÃO. Diálogos (Mênon). 2. ed. Porto Alegre: Globo, 1950.

TEDESCO, J. C. Educar en la sociedad del conocimiento. Buenos Aires: Fondo de Cultura Económica, 2002.

ZAMPERETTI, M. P. Formação Docente e Autorreflexão: práticas pedagógicas coletivas de si na escola. Tese (Doutorado em Educação), 2012. 


\section{Wagner de Moura Oliveira.}

Santa Maria, Rio Grande do Sul, Brasil

Graduado em História Licenciatura Plena e Bacharelado pela Universidade Federal de Santa Maria. Mestrando do Programa de Pós-graduação em Educação Profissional e Tecnológica da UFSM, atuando na linha de pesquisa de Formação Docente para a Educação Profissional e Tecnológica. Email: wagnermoura56@gmail.com

Link do Lattes: http://lattes.cnpq.br/3809894962561440

\section{Francisco Nilton Gomes de Oliveira.}

Santa Maria, Rio Grande do Sul, Brasil

Possui graduação em Terapia Ocupacional pela Universidade de Fortaleza, Mestrado em Psicologia pela Universidade de Fortaleza, Doutorado em Linguística pela Universidade Federal de Pernambuco e Pós Doutorado em Educação na Universidade Federal do Rio Grande do Sul- UFGRS. Atualmente é Professor Adjunto da Universidade Federal do Rio de Janeiro- UFRJ, Faculdade de Medicina Departamento de Terapia Ocupacional, docente do Mestrado Educação Profissional e Tecnológica no Colégio Técnico Industrial na Universidade Federal de Santa Maria, na linha de pesquisa: Políticas e Gestão em Educação Profissional e Tecnológica. Acumula experiência na área de Gestão em Educação superior, Direção de Ensino, Coordenação de cursos, Coordenação do Programa em Saúde Mental, Tutor e Preceptor da Residência Multiprofissional da UFSM. Avaliador de cursos do BASIS- INEP/MEC. Linhas de Pesquisas: Gestão em Educação Superior: Políticas públicas, Gestão e Avaliação, Interdisciplinaridade, bem como na Terapia Ocupacional em Saúde Mental, Saúde Coletiva e Campo Social. Autor dos Livros: O universo linguístico: uma releitura filosófica na linguagem humana; Cenários e determinantes na educação superior no Brasil: caminhos reflexões sobre as práticas institucionais de ensino e Educação Superior: refletindo caminhos e compartilhando relatos de experiências, modelos e experiências de uma rede de atenção em saúde mental e Acessibilidade Cultural no Brasil: narrativas e vivências em ambientes sociais. Atualmente é Pesquisador na Rede de Estudos em Universidade (Rede GEU) da Universidade Federal de Santa Maria- UFSM, numa interlocução interinstitucional das Universidades Federais de Santa Maria (UFSM) e Porto Alegre (UFRGS) e Docente do Programa de Pós-Graduação de Educação Profissional e Tecnológica do Colégio Técnico Industrial de Santa MariaUFSM.

Email: niltonufrj@gmail.com

Link do Lattes: http://lattes.cnpq.br/8810489697768335

\section{Roselene Moreira Gomes Pommer}

Santa Maria, Rio Grande do Sul, Brasil

Licenciada em História pela Universidade Federal de Santa Maria (1987), Mestre em História pela Universidade do Vale do Rio dos Sinos (2002) e Doutora em História pela Universidade do Vale do Rio dos Sinos (2008). Docente da Universidade Federal de Santa Maria, atuando no Colégio Técnico Industrial - CTISM e no Programa de Pós-Graduação em Educação Profissional e Tecnológica Mestrado Acadêmico em Educação Profissional e Tecnológica. Tem experiência na área de História e Ensino da História, com ênfase em História Latino-Americana, principalmente nas seguintes temáticas: identidade e memória; ações culturais e processo reducional jesuítico-guarani; Ensino da História em Cursos Técnicos Integrados e Mundos do Trabalho.

Email: roselenepommer@ctism.ufsm.br

Link do Lattes: $\underline{\text { http://lattes.cnpq.br/1635475892372110 }}$

Recebimento: $25 / 07 / 2020$

Aprovação: 09/10/2020 


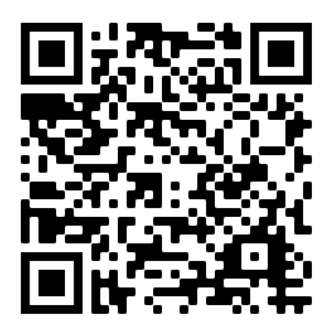

\section{Q.Code}

\section{Editores-Responsáveis}

Dr. Enéas de Araújo Arrais Neto, Universidade Federal do Ceará, UFC, Ceará, Brasil

Dr. Sebastien Pesce, Universidade de Orléans, França 